\title{
Study on the Reform of General College Physical Education Curriculum System
}

\author{
Shiqian $\mathrm{YaO}^{1, \mathrm{a}}$ \\ ${ }^{1}$ Wuhan Technology and Business University, Wuhan, Hubei, China, 430065 \\ a email
}

Keywords: Curriculum System, College Physical Education

\begin{abstract}
College Physical Education should actively adapt to the reform and development of fundamental education must be to foster new PE teachers as a starting point and destination, culture financial knowledge, ability and quality as one of the new physical education personnel in line with the needs of society. However, our various between institutions of higher learning of Physical Education in Primary and Secondary Curriculum with New Standard No good butt, which also led to disjointed professional training objectives and content of Physical Education and sports school curriculum reform in between. So on Campus Physical Education Curriculum to investigate whether personnel training to meet the needs of basic education sports courses, to studies of both contacts is necessary.
\end{abstract}

\section{Introduction}

Physical education curriculum reform after several times, and achieved fruitful results, constantly improve the quality of personnel training as a whole, but because of this lack of curriculum reform and practice integrity, resulting in the presence of knowledge and learning in personnel training, capacity-building character education isolated phenomenon, the overall characterization of the course structure of the traditional and the one-line-oriented, curriculum Jiang Gu, course content outdated curriculum backward management Teaching methods boring, seriously hurt the students' enthusiasm, resulting in their teaching ability and poor scientific awareness, lack of capacity to educational practice, physical education creativity is not strong. In the process of implementation of the teaching process, the ability to develop a culture and personality is lack normative and operational focus and difficulty difficult to implement training, and then to make the curriculum reform in trouble. Curriculum reform for lack of integrity, practical and operational problems, a comprehensive reform of how a knowledge-based courses, to achieve integration of the one-sidedness overcome, is the direction of the world curriculum reform and development. The need for curriculum reform and integration of research, is key to its success: in theory, overcome the imperfections and limitations of the study curriculum, to build a new integration of the curriculum theory; in practice, institutionally, the national level research experts curriculum ideas and research school level curricula for teachers, organically combine the development of new curriculum ideas reflect modern teaching techniques. Through theoretical innovation, capacity-building is as the center, the establishment of the theory and practice of organic combination of integration of sports professional competence-based education curriculum theory.

\section{Basic Principles of Physical Education Curriculum System Reform}

According to the needs and demands of Physical Education Personnel diversified development trend in the 21st century higher education development, implementation. Health first guiding ideology, closely linked to the requirements of quality education, to follow the moral, intellectual, physical, and aesthetic development approach reflects. Three-oriented spirit of the times, around the physical education professional training objectives and standards of training provided to adapt to 21st century education curriculum development needs. Curriculum design is set mainly during the following several important principles:

Comprehensive Principles. Adhere to the coordinated development of knowledge, ability and 
quality, so that students can adapt and build lifelong education and social change and development needs of the overall quality of construction.

Adaptability Principles. We need to strengthen the foundation and broaden the professional caliber, deepen reform and promote professional culture thick foundation, wide caliber, high-quality, strong ability to adapt to a wide, heavy innovative physical education personnel to adapt to the social development needs.

The Principle of Subjectivity. Adhere to the student-centered, individualized, focus on personality development. It is necessary to consider the basic needs of all students and the general requirements, but also consider the differences between students and other students, so that each student to be fully developed.

Scientific Principles. Adhere to a comprehensive curriculum and overall optimization system, build a reasonable, flexible curriculum area and curriculum modules, the rational allocation of curriculum structure and strengthen cross-integration between different disciplines.

Operability Principles. Curriculum system and teaching content of deepening reform is necessary to speed up the on foot, but also based on reality, taking into account the specific conditions of different schools, the implementation of national, local, and school levels curriculum management, increasing school autonomy, and enhance the curriculum for local schools student adaptability.

Educational reform must be to update the ideas of education for the pilot. Does not change the concept of education, reform is difficult to have any real breakthrough. New Century Physical Education to train. Thick foundation, wide caliber, strong ability, re-innovation, adapt to a wide compound talents to meet the needs of social development and basic education reform and development, it is necessary to update the concepts of education, establish the idea of lifelong education, and change the past, according to a single model students concept, emphasizing individualized, attention to the development of students' good personality and expertise. Setting fitness health education courses in the new program, such as traditional fitness theory and methods, sports Environment and Health, rehabilitation science, health science, health education, exercise principles and methods to promote the comprehensive teaching concepts and curriculum content system reform. Especially in technical subjects teaching content change in terms of the traditional tendency to project-based athletics, highlighting them as ways and means of fitness function.

\section{Reform Strategy of Physical Education Curriculum System}

Adhere to the principle of moral, intellectual, physical and aesthetic development and knowledge, ability, quality and coordinated development. According to strengthen the foundation and broaden the professional caliber, focus on quality education and capacity building, reinforcing the idea of the adaptability of graduates, rebuild curriculum. Establish active adaptation of educational concepts of economic construction, social development and human comprehensive development, strengthen cultural quality education of college students in particular, humanistic quality education, so that students can form the basics of lifelong education and sustainable development needs, abilities and qualities structure, and strive to become moral, intellectual, physical and aesthetic development and having a harmonious sound personality and individuality expertise.

Adhere to the student-centered, comprehensive implementation of individualized, focusing on the principle of personality development. Student-centered, promote the comprehensive development has become an important part of modern educational philosophy and educational practice to be reflected. It is necessary to consider the basic needs of all students and the general requirements, but also consider other differences between students, so that each student have been fully developed. Focus on personalized, comprehensive education.

We need to strengthen the foundation and broaden the caliber, desalination discipline, intensive courses, horizontal integration and the principle of open lengthwise. In developing the new curriculum plan process, reasonable arrangements for each Course Group PE ratio between education, strengthen all kinds of class group, communication between the various disciplines, focusing on curriculum system miniaturization, localization, personalization and integration. 
Strengthen the combination of dominant and recessive course curriculum, focusing on unified general education and special education, unified theory and practice of science education and humanities and social science education, and continuously improve teaching quality and efficiency. To the modern educational concepts as a guide, follow the basic law of education and teaching and adhere to the basic principle of undergraduate education and teaching content, reflecting the basic stages and undergraduate education. Theory with practice, strengthen practical training, knowledge transfer should pay attention to content updates and frontier knowledge and learning and students are focus on innovation. Strengthen the comprehensive sex education, to broaden the basis for a range of disciplines, reflecting the interdisciplinary integration. From an emphasis on professional counterparts to broaden the professional caliber in order to enhance the adaptability of transition; from a purely professional education to general education and professional education combined transition; from a single mode of personnel training to the diversity and unity of the combination model.

Modular course combinations, a breakthrough in the overall assembly line courses. Select different combinations to suit different needs of society, such as only provides various courses mandatory school scores and the number of gates, or by the school and the students choose courses according to different modules module courses or elective provisions only hours, not specified course.

Around physical education professional training objectives and training specifications, from the specific design training mode, refer to the basic idea of the world and our curriculum reform, dilute the independent status of the curriculum, strengthen the overall curriculum system for different courses of general requirements overall optimization of the principles of curriculum system and teaching content reform. Construction of Curriculum System platform from the point of view, from macro to micro, from theory to practice, from portrait to landscape, and further expand on different levels, to enhance the quality of personnel training.

Updating educational ideas and concepts of science and determine the physical education professional training objectives of the pilot. Updating educational ideas and concepts of the past is to abandon teaching ideas and concepts, through summary and reflection, to carry forward the past useful side, which eliminated outdated educational ideas and concepts. Educational reform ideas and concepts are actually educational phenomenon, and then re-deepening understanding of the nature and law or under the new situation. Reform of educational ideology, to re-examine the talent training plan has laid a good foundation, such as, "quality education" concept requires that the education goals of comprehensive, integrated model of culture, the culture coordination process, "lifelong learning" concept establish requirements for the training process of the stage, the basic continuity and teaching contents, validity, the concept "emphasis on personal development" requires that the education and training of diverse models of relaxed environment. Faced with the progress of the development of the new century, social education, face a new round of basic education curriculum reform, social development must be based on different levels, different specifications, different types of high-level expertise of the objective requirements of the physical education major talent Training objectives for accurate positioning.

As can be seen from the College Physical Education professionals in training mode Historical Changes, Physical Education Major's position is: First, physical education undergraduate higher education system belongs, in terms of its properties, which should reach the professional undergraduate education the general level and requirements that you must have the professional education of the general characteristics; second, professional and physical education teachers belong to the education system, which requires from the particularity of teacher education system up awareness of Physical Education Major. Based on the above research and understanding of the physical education professionals of culture in the new century put forward new requirements, training objectives expressed in the new physical education specialty new course program as: "Physical Education Major train qualified school physical education, teaching, training and competition work, and to engage in complex Physical Education personnel school sports science, sports management and school social sports guidance work. 


\section{Conclusion}

In short, according to the "wide caliber, thick foundation, strong ability, high quality, wide adaptation, re-innovation," the new training model requirements, according to "strengthen basic broaden caliber, optimize the structure, to streamline the content, expanded elective prominent personality practice-oriented, forming characteristics, "the principle," to broaden the base, strengthening capacity, improve the quality of "main line," the goal to design, build framework, reassembly module, the overall optimization of the new curriculum plan "for the process, well-designed practical. And with the development of the times, in succession reflection, supplement and improve the development Criticism, innovation and improvement, innovation in succession, in the reform and development of continuous improvement.

\section{References}

[1] Stenhouse, L. An Introduction to Curriculum Research and Development, 2001

[2] Scriven M. The methodology of evaluation Perspectives of curriculum evaluation: Vol 1. AERA Monograph series on curriculum evaluation, 1999

[3] Snyder J, Bolin F, Zunwalt K. Curriculum implementation. Handbook of Research on Curriculum, 2007

[4] Fullan M, Stiegelbauer S. The New Meaning of Educational Change. 1998

[5] Tyler RW. Basic principles of curriculum and instruction. 2009

[6] Daniel Tanner, Laurel N Tanner. Curriculum Development: Theory into Practice. 2003 